\title{
Assessment of pain during rest and during activities in the postoperative period of cardiac surgery
}

\author{
Larissa Coelho de Mello ${ }^{1}$ \\ Silvio Fernando Castro Rosatti ${ }^{2}$ \\ Priscilla Hortense ${ }^{3}$
}

Objective: to assess the intensity and site of pain after Cardiac Surgery through sternotomy during rest and while performing five activities. Method: descriptive study with a prospective cohort design. A total of 48 individuals participated in the study. A Multidimensional Scale for Pain Assessment was used. Results: postoperative pain from cardiac surgery was moderate during rest and decreased over time. Pain was also moderate during activities performed on the $1^{\text {st }}$ and $2^{\text {nd }}$ postoperative days and decreased from the $3^{\text {rd }}$ postoperative day, with the exception of coughing, which diminished only on the $6^{\text {th }}$ postoperative day. Coughing, turning over, deep breathing and rest are presented in decreased order of intensity. The region of the sternum was the most frequently reported site of pain. Conclusion: the assessment of pain in the individuals who underwent cardiac surgery during rest and during activities is extremely important to adapt management and avoid postoperative complications and delayed surgical recovery.

Descriptors: Thoracic Surgery; Pain, Postoperative; Pain Measurement.

\footnotetext{
1 MSc, RN, Irmandade da Santa Casa de Misericórdia de São Carlos, São Carlos, SP, Brazil.

${ }^{2}$ Doctoral student, Universidade Federal de São Carlos, São Carlos, SP, Brazil. Physician, Irmandade da Santa Casa de Misericórdia de São Carlos, São Carlos, SP, Brazil.

${ }^{3}$ PhD, Adjunct Professor, Departamento de Enfermagem, Universidade Federal de São Carlos, São Carlos, SP, Brazil.
}

Corresponding Author: Larissa Coelho de Mello Alameda das Orquídeas, 840 Bairro: Cidade Jardim CEP: 13566-520, São Carlos, SP, Brasil E-mail: larissac_enf@yahoo.com.br
Copyright (c) 2014 Revista Latino-Americana de Enfermagem This is an Open Access article distributed under the terms of the Creative Commons Attribution Non-Commercial License (CC BY-NC).

This license lets others distribute, remix, tweak, and build upon your work non-commercially, and although their new works must also acknowledge you and be non-commercial, they don't have to license their derivative works on the same terms. 


\section{Introduction}

Despite advancements achieved in the technique of surgeries to treat ischemic and valvular heart diseases, pain is still the main manifestation reported by patients who undergo cardiac surgery, possibly accounting for complications and delays in recovery. Studies show that from $47 \%$ to $75 \%$ of patients report pain in the postoperative (PO) period of cardiac surgery ${ }^{(1)}$.

Surgery, especially when performed in the thorax or abdomen, associated with PO pain, hinders ventilation, coughing and deep breathing, thus reducing the elimination of secretion from the respiratory tract, decreasing vital lung and functional residual capacity, leading to atelectasis and respiratory infections, among other results(2-3). In addition to the unpleasant aspect and physiological repercussions of PO pain, it also delays patients' return to mobility and hospital discharge ${ }^{(4)}$.

Therefore, assessment of PO pain should not be performed only when the patient is resting, because patients rapidly initiate activities to prevent $\mathrm{PO}$ complications. Assessment of each activity that causes discomfort, such as coughing, respiratory exercises, manipulation by the health staff or procedures considered to be painful, is also recommended. A comprehensive assessment of pain followed by appropriate treatment optimizes the performance of activities and fast recovery ${ }^{(1)}$

Untreated acute pain may become chronic pain. The incidence of post-sternotomy chronic pain ranges from $18 \%$ to $61 \%$ in different samples ${ }^{(5-6)}$. One study with individuals who were treated with sternotomy ${ }^{(7)}$ reports that those with acute $\mathrm{PO}$ pain of moderate to severe intensity were more likely to experience chronic pain one year after the surgery.

The literature and empirical practice suggest that cardiac surgery patients experience pain related to surgical factors and activities that are expected in the PO period. Such a fact can decrease motivation for treatment and negatively influence $P O$ recovery. Therefore, efficient assessment and measurement of pain is required in order to properly manage it. Assessing and measuring pain is, however, a challenge due to the complexity, subjectivity and multidimensional nature of a painful phenomenon(8).

Better identification of PO pain characteristics and their repercussions is the first step to devising strategies to improve pain management. Therefore, this study's objectives were to assess the patients' perceptions of pain (intensity and site) after median sternotomy for cardiac surgery on the $1^{\text {st }}, 2^{\text {nd }}, 3^{\text {rd }}$ and $6^{\text {th }}$ PO days during rest and when performing five expected activities (coughing, turning over, deep breathing, sitting or standing up from a chair and walking) and to make associations between intensity of post cardiac surgery pain and rest and expected activities, considering the days $\mathrm{PO}$.

\section{Method}

This is a descriptive exploratory study with a prospective cohort design. The study project was approved by the Institutional Review Board at the Federal University of São Carlos (UFSCAR), SP, Brazil (Process No. 358/2011). All the participants voluntarily signed free and informed consent forms.

Data were collected in a Coronary Care Unit and a Surgical Clinical Unit of a non-profit hospital in a city in the interior of São Paulo. A convenience sample was used and data were collected between November 2011 and July 2012. Inclusion criteria were: being 18 years old or older; having no difficulty understanding the tasks requested during the survey; having undergone myocardial revascularization or valve replacement via median sternotomy; and the surgery in question should be the patient's first experience with cardiac surgery. Exclusion criteria were: individuals requiring intubation in the immediate $\mathrm{PO}$; patients who experienced complications after the surgery, such as stroke or extensive hemorrhaging; and those who died during the surgical process or during the first six days post surgery.

Socio-demographic and clinical data were collected during the preoperative period, such as gender, age, height, ethnicity, history of smoking or alcohol abuse, and chronic diseases like hypertension, diabetes mellitus, chronic renal failure or dyslipidemia.

After surgery, when patients were already in the Coronary Care Unit, surgical information was collected concerning the type of surgery, use of thoracic or mediastinal drain, and duration of surgery. The patients were received pain assessment (intensity and site) during rest and while performing activities on the $1^{\text {st }}, 2^{\text {nd }}, 3^{\text {rd }}$ and $6^{\text {th }}$ PO day, namely coughing, turning over, deep breathing, sitting or standing up from a chair and walking. The researcher assessed the participants at the end of each day to verify whether they recalled experiencing pain during activities and at rest. The Multidimensional Pain Evaluation Scale was used to assess intensity and the site(s) of pain. 
This scale was validated for the Portuguese language by Sousa et al.(9) and contains the Pain Rating Scale, which assesses the intensity of pain and ranges from 0 to 10 (zero meaning absence of pain and 10 the "worst imaginable pain") and the Body Diagram that assesses the site of pain and pain descriptors to assess language.

A statistical exploratory assessment was initially performed using central tendency measures, standard deviation and percentages. The use of non-parametric statistical tests was required for dependent data (the same individuals for each day compared in each activity): Friedman and Wilcoxon matched pairs. The level of significance was fixed at $5 \%$.

\section{Results}

A total of 54 individuals were included in the study but five of these died during the surgical procedure or during the first six days PO due to complications, while one individual was submitted to another type of surgical incision. Therefore, the final sample was composed of 48 people.

Most patients were male (75\%). The average age was 58.6 years old, ranging from 28 to 77 years old, while $54.2 \%$ were above the age of 60 years of age. In regard to Body Mass Index (BMI), 70.8\% were overweight or obese according to the World Health Organization classification(10). Concerning ethnicity, most were characterized as Caucasian $(91.7 \%)$ (Table 1).

In regard to the clinical variables, we observed that $62.5 \%$ of the participants were smokers and $87.5 \%$ shared the medical diagnosis of hypertension. Other chronic diseases, such as diabetes mellitus, chronic renal insufficiency and dyslipidemia were less frequent. In terms of surgical variables, $56.3 \%$ were submitted to myocardial revascularization and $43.8 \%$ to valve replacement. A mediastinal drain was used in all the surgeries while a thorax drain was used by only $4.2 \%$ of the patients. The duration of surgeries ranged from 160 to 325 minutes, with an average of 229.6 min, or 3 h50min.

In regard to pain, all the patients complained at least once during one of the post surgery activities. Over time, the average of the pain intensity decreased in all the activities post surgery, with the exception of sitting or standing up from a chair. The average intensity of pain during this activity on the $1^{\text {st }}$ day PO was $4.00(n=1)$ and on the $2^{\text {nd }}$ day PO the average increased to $5.13(n=16)$. We note, however, that only one individual sat or stood up on the $1^{\text {st }}$ day PO, while 16 individuals performed this activity on the $2^{\text {nd }}$ day PO. Hence, this fact hinders any analysis concerning this activity (Table 2).

Table 1 - Distribution of the number of people undergoing cardiac surgery according to socio-demographic characteristics (gender, age, Body Mass Index and ethnicity). São Carlos, SP, Brazil, 2011-2012

\begin{tabular}{|c|c|c|c|c|c|}
\hline Variables & $\begin{array}{c}\text { Frequency } \\
\text { (N) }\end{array}$ & $\%$ & Min & Max & Average \\
\hline \multicolumn{6}{|l|}{ Gender } \\
\hline Male & 36 & 75 & & & \\
\hline Female & 12 & 25 & & & \\
\hline Age & & & 28 & 77 & 58.6 \\
\hline 18 to 29 years old & 1 & 2.1 & & & \\
\hline 30 to 39 years old & 2 & 4.17 & & & \\
\hline 40 to 49 years old & 8 & 16.7 & & & \\
\hline 50 to 59 years old & 11 & 22.9 & & & \\
\hline 60 years old or older & 26 & 54.2 & & & \\
\hline \multicolumn{6}{|l|}{ Body mass index } \\
\hline$<18.5$ & - & & & & \\
\hline 18.5 to 24.9 & 14 & 29.2 & 20.6 & 24.8 & 23.1 \\
\hline 25 to 29.9 & 22 & 45.8 & 25 & 29.9 & 27.2 \\
\hline$>30$ & 12 & 25 & 30.4 & 47.9 & 33.6 \\
\hline \multicolumn{6}{|l|}{ Ethnicity } \\
\hline Caucasian & 44 & 91.7 & & & \\
\hline African descendent & 2 & 4.17 & & & \\
\hline Mixed & 2 & 4.17 & & & \\
\hline
\end{tabular}

The highest average intensity of pain on the $1^{\text {st }}$ day PO was reported for the activity turning over, while the highest average reported on the $2^{\text {nd }}, 3^{\text {rd }}$ and $6^{\text {th }}$ days PO was reported for coughing (Table 2).

In regard to the comparison of intensity of pain during rest during the days $\mathrm{PO}$, we conclude that all the results obtained from the assessed days were statistically different, that is, pain diminished over time. Only on the $6^{\text {th }}$ day PO did patients experience reduced pain while coughing (Table 3 ).

The intensity of pain experiencing during the activity turning over was similar on the first two days, while important statistically significant differences were found for the $3^{\text {rd }}$ and $6^{\text {th }}$ days PO; that is, the intensity of pain while turning over was the same for the first two days and started to decrease from the 3rd day on. No statistical difference was found in the intensity of pain experienced during deep breathing between the first and the second days, though important statistical differences were found for all the other comparisons: pain decreased over time (Table 3 ). 
Table 2 - Distribution of pain intensity (average, minimum, maximum and standard deviation) among individuals (N) in the postoperative period of cardiac surgery during rest and activities, according to days postoperative. São Carlos, SP, Brazil, 2011-2012

\begin{tabular}{|c|c|c|c|c|c|c|c|}
\hline Variable & Postoperative & Average & Min & Max & $\begin{array}{l}\text { Standard } \\
\text { deviation }\end{array}$ & $\begin{array}{l}\text { Number of } \\
\text { individuals }\end{array}$ & $\%$ \\
\hline \multirow[t]{4}{*}{ Rest } & $1^{\text {st }}$ & 3.90 & 0 & 10 & 3.07 & 21 & 44 \\
\hline & $2^{\text {nd }}$ & 3.04 & 0 & 10 & 2.92 & 14 & 29 \\
\hline & $3^{\text {rd }}$ & 1.98 & 0 & 8 & 2.70 & 12 & 25 \\
\hline & $6^{\text {th }}$ & 0.98 & 0 & 8 & 2.03 & 7 & 15 \\
\hline \multirow[t]{4}{*}{ Cough } & $1^{\text {st }}$ & 6.33 & 0 & 10 & 2.88 & 38 & 79 \\
\hline & $2^{\text {nd }}$ & 6.08 & 0 & 10 & 2.92 & 40 & 83 \\
\hline & $3^{\text {rd }}$ & 5.35 & 0 & 10 & 2.71 & 41 & 85 \\
\hline & $6^{\text {th }}$ & 4.02 & 0 & 10 & 2.32 & 43 & 90 \\
\hline \multirow[t]{4}{*}{ Turn over } & $1^{\text {st }}$ & 6.48 & 1 & 10 & 2.61 & 42 & 88 \\
\hline & $2^{\text {nd }}$ & 5.23 & 0 & 10 & 2.53 & 41 & 85 \\
\hline & $3^{\text {rd }}$ & 3.90 & 0 & 10 & 2.72 & 35 & 73 \\
\hline & $6^{\text {th }}$ & 1.38 & 0 & 8 & 1.99 & 18 & 38 \\
\hline \multirow[t]{4}{*}{ Deep breathing } & $1^{\text {st }}$ & 4.83 & 0 & 10 & 2.89 & 38 & 79 \\
\hline & $2^{\text {nd }}$ & 4.31 & 0 & 10 & 2.69 & 38 & 79 \\
\hline & $3^{\text {rd }}$ & 3.31 & 0 & 10 & 2.75 & 35 & 73 \\
\hline & $6^{\text {th }}$ & 1.56 & 0 & 10 & 2.06 & 24 & 50 \\
\hline \multirow[t]{4}{*}{ Sitting or standing up } & $1^{\text {st }}$ & 4.00 & 4 & 4 & 0.00 & 1 & 2 \\
\hline & $2^{\text {nd }}$ & 5.13 & 3 & 10 & 2.18 & 16 & 33 \\
\hline & $3^{\text {rd }}$ & 4.09 & 0 & 8 & 2.37 & 29 & 60 \\
\hline & $6^{\text {th }}$ & 2.92 & 0 & 10 & 2.23 & 37 & 77 \\
\hline \multirow[t]{4}{*}{ Walking } & $1^{\text {st }}$ & - & - & - & - & - & - \\
\hline & $2^{\text {nd }}$ & 5.00 & 5 & 5 & 0.00 & 1 & 2 \\
\hline & $3^{\text {rd }}$ & 1.23 & 0 & 6 & 2.20 & 5 & 10 \\
\hline & $6^{\text {th }}$ & 0.58 & 0 & 6 & 1.42 & 10 & 21 \\
\hline
\end{tabular}

We could only analyze data concerning the $3^{\text {rd }}$ and $6^{\text {th }}$ days $\mathrm{PO}$ of the activities sitting or standing up from a seated position and walking because very few patients were able to perform these activities during the first two days. Statistical differences in the intensity of pain from sitting or standing up were found between the $3^{\text {rd }}$ and $6^{\text {th }}$ days PO; pain was less intense on the $6^{\text {th }}$ day, while no statistical differences were found for the walking activity between these two days (Table 3).

Table 3 - Results obtained ( $p$-values) through the Wilcoxon-matched test for all the variables comparing postoperative days. São Carlos, SP, Brazil, 2011-2012

\begin{tabular}{lccccc}
\hline \multirow{2}{*}{ Variable } & \multirow{2}{*}{ Postoperative } & \multicolumn{5}{c}{ p-value } \\
\cline { 3 - 6 } & & $\mathbf{1}^{\text {st }}$ postoperative & $\mathbf{2}^{\text {nd }}$ postoperative & $\mathbf{3}^{\text {rd }}$ postoperative & $\mathbf{6}^{\text {th }}$ postoperative \\
\hline Rest & $1^{\text {st }}$ & - & - & - & - \\
& $2^{\text {nd }}$ & 0.002837 & - & - & - \\
& $3^{\text {rd }}$ & $6.754 \times 10^{-5}$ & 0.0002289 & - & - \\
Cough & $6^{\text {th }}$ & $2.017 \times 10^{-6}$ & $1.781 \times 10^{-6}$ & 0.000985 & - \\
& $1^{\text {st }}$ & - & - & - & - \\
& $2^{\text {nd }}$ & 0.7652 & - & - & - \\
Turning over & $3^{\text {rd }}$ & 0.06193 & 0.1741 & - & - \\
& $6^{\text {th }}$ & $7.339 \times 10^{-6}$ & 0.0002614 & - & - \\
& $1^{\text {st }}$ & - & - & - & - \\
& $2^{\text {nd }}$ & 0.06309 & - & - & -
\end{tabular}


Table 3 - (continuation)

\begin{tabular}{lccccc}
\hline \multirow{2}{*}{ Variable } & \multirow{2}{*}{ Postoperative } & \multicolumn{4}{c}{$\mathbf{p}$-value } \\
\cline { 3 - 6 } & $\mathbf{1}^{\text {st }}$ postoperative & $\mathbf{2}^{\text {nd }}$ postoperative & $\mathbf{3}^{\text {rd }}$ postoperative & $\mathbf{6}^{\text {th }}$ postoperative \\
\hline Deep breathing & $1^{\text {st }}$ & - & - & - & - \\
& $2^{\text {td }}$ & 0.1267 & - & - & - \\
Sitting or standing up & $3^{\text {rd }}$ & 0.002144 & 0.0017 & - & - \\
Walking & $6^{\text {th }}$ & $1.126 \times 10^{-6}$ & $9.551 \times 10^{-7}$ & $2.77 \times 10^{-6}$ & - \\
\hline
\end{tabular}

Intensity of pain was compared during rest and the activities of coughing, turning over, and deep breathing and the indexes found are not statistically equal. Intensity of pain was the highest for coughing (5.44), followed by turning over (4.24), deep breathing (3.50) and rest (2.47).

In regard to the site of pain, we verified that at all the points in time assessed, surgical incision in the sternum region was the site most frequently reported by the individuals (94\%), followed by the epigastric region $(75 \%)$, right and left breasts (46\% each site) and cervical and interscapular (25\%) areas. Other sites were reported with a lower frequency.

\section{Discussion}

We observed that post-cardiac surgery pain was mild during rest and decreased over time. During activities, however, pain intensity was moderate in the first two days after surgery and decreased from the $3^{\text {rd }}$ day on, with the exception of coughing, the intensity of which diminished only on the $6^{\text {th }}$ day PO.

Similar results were found in a study addressing individuals' post cardiac surgery, which reports that these individuals are less likely to perform activities if they cause pain. The authors analyzed the activities of getting out of bed, sitting or standing up from a chair, standing up and walking and decreased mobility was reported as being among the most common effects in the presence of pain(11). In this study, we observed that a reduced number of individuals performed the activities sitting or standing up and walking, possibly to avoid performing activities that cause pain.

When compared to each other for the four days assessed, the following variables presented the highest averages of pain intensity, in decreasing order: coughing, turning over, deep breathing, and while at rest. The results suggest there is a need to pay attention to the appropriate management of post cardiac surgery pain, especially during activities. Nursing actions should focus on the assessment and measurement of pain to enable acquiring knowledge about its existence, intensity and other aspects, not only while at rest but especially during activities that are required to avoid complications. Assessment and measurement of pain can guide interventions directed to pain management.

Coughing was the activity that presented the highest pain intensity and longest duration; a relevant decrease in pain was observed on the last day studied. Coughing, generally induced after physical therapy, is an activity that eliminates accumulated lung secretions and, if performed frequently, reduces the chances of delayed surgical recovery. A prior study involving 705 individuals who underwent cardiac surgery, the objective of which was to identify pain and associate it to various types of activities in the six first days of hospitalization, observed that these individuals also experienced pain during the entire study period but that it decreased over time. Coughing was also the activity in which the individuals reported experiencing the highest intensity of pain, followed by moving or turning over in bed, standing up from chair or walking, deep breathing or using an incentive spirometer and during rest. These authors found that the levels of pain, even on the $6^{\text {th }}$ day PO ranged from no pain to intense pain, confirming the need to individually assess and treat PO pain(2).

Another study was conducted to assess intensity of pain in relation to some activities in the post cardiac surgery period in 102 patients. Also in that study, the activity most frequently associated with pain was coughing (95.1\%). All the other activities (physical therapy, passive movement and self-movement) were associated with pain at least some of the time by more than $80 \%$ of the participants ${ }^{(12)}$.

Various studies ${ }^{(13-16)}$ indicate that management of PO pain after cardiac surgery is extremely important 
if we consider the alterations that accrue from this phenomenon, that is, one of the main strategies to prevent complications is pain management.

Other authors assessed pain relating it to lung function in 70 adults who underwent cardiac surgery via sternotomy. They observed significant impairment of lung function, which did not return to its preoperative performance until the $5^{\text {th }}$ day PO. They associated such impairment with the presence of pain ${ }^{(13)}$.

A study was conducted with 30 patients in a post cardiac surgery Intensive Care Unit in the first four days PO to assess intensity of pain, identify potential associations among physiological changes and $\mathrm{PO}$ pain, and describe analgesia used. The results showed an association and positive correlation between pain and the presence of physiological changes, while the most frequent were tachypnea and increased blood pressure. In regard to analgesia, only the administration of medication was used and most was administered under the scheme "medical discretion". A total of $86.7 \%$ of the studied sample experienced pain at least once. Most patients reported pain on the $1^{\text {st }}$ and $2^{\text {nd }}$ days $\mathrm{PO}$, while the highest incidence of pain occurred on the $1^{\text {st }}$ day PO $(63.3 \%)^{(14)}$.

Another study addressing 22 patients submitted to mid-sternal thoracotomy cardiac surgery assessed the extent to which pain affects functional independence. A total of $54.5 \%$ of the participants reported moderate pain on the $2^{\text {nd }}$ and $3^{\text {rd }}$ days $\mathrm{PO}$ and $63.6 \%$ experienced mild pain on the $5^{\text {th }}$ and $6^{\text {th }}$ days $P O$. This same study reports that the highest intensity of pain reported by patients worsened with cough and/or deep breathing. Surgical intervention changed the functional performance of these individuals. Loss of functional performance was observed on the $2^{\text {nd }}$ and $3^{\text {rd }}$ days PO compared to the preoperative period, while increased functionality was observed when comparing the $2^{\text {nd }}$ and $3^{\text {rd }}$ days PO to the $5^{\text {th }}$ and $6^{\text {th }}$ days $\mathrm{PO}{ }^{(15)}$. Decreased pain, experienced over time after surgery, was one of the factors that might have influenced the increased functional score for the $6^{\text {th }}$ and $5^{\text {th }}$ days $\mathrm{PO}$ in comparison to the $2^{\text {nd }}$ and $3^{\text {rd }}$ days $\mathrm{PO}^{(15)}$.

A Brazilian study assessed pain intensity during the $1^{\text {st }}, 3^{\text {rd }}$ and $4^{\text {th }}$ days $\mathrm{PO}$ and its repercussion on the respiratory function of 31 patients who underwent elective cardiac surgery. The results showed that the average intensity of pain was 8.32 on the analogical visual scale and reduced the respiratory function of patients, hindering deep inspirations, especially on the $1^{\text {st }}$ day $\mathrm{PO}^{(16)}$.
In regard to the site of pain, this study showed that a surgical incision in the sternum region was the site most frequently reported if we consider all the times and situations assessed. Most individuals (94\%) reported pain in the sternum while coughing for all the days assessed. This is an expected situation, since the surgical incision was performed via median sternotomy. The second most frequently reported site of pain was the epigastric region, which is where the mediastinal drain is inserted, followed by the right and left breast regions. These regions were probably considered painful due to the active movement of the ribs during the surgical procedure. The cervical and interscapular regions, where the posterior thorax is located, were also perceived as sites of pain, probably because of the persistent supine position of the individuals in bed.

Some authors found the same results. One study assessed 200 adults after cardiac surgery in regard to the site, distribution (number of sites where the patient experienced pain) and intensity of pain on the $1^{\text {st }}, 2^{\text {nd }}$, $3^{\text {rd }}$ and $7^{\text {th }}$ days PO.

The authors observed that pain was significantly more intense during the first two days after the surgery; with reports of moderate pain. The intensity of pain started to diminish from the $3^{\text {rd }}$ day PO on. The sites where there was a higher level of pain was the incisional area (sternum) and the epigastric region. We observed that the site of pain changed over time. The number of patients with incisional pain and pain in the epigastric region was reduced, probably because the drains were removed, and musculoskeletal pain (back and shoulders) predominated at the end of the first week. The authors conjecture that this was probably due the active mobilization of articulations in the sternum, which, during surgery, remain tense due to the bone retraction, as well as muscle spasms related to the surgical positioning and prolonged total bed rest(17)

One Brazilian study of elective cardiac surgery patients reports that the site where pain was most frequently reported was the sternum $(50 \%)^{(16)}$. Another study reports that the most painful site was the sternum region and the second most reported site of pain was the thoracic spine region $(\mathrm{T} 10)^{(13)}$. And yet another study reports that the sternum incision and the drain insertion were the most common sites of pain reported by the patients for all the points of time assessed ${ }^{(18)}$.

When carefully assessing patients with pain in a delicate time such as after major surgery, the professional 
becomes the "one to rely on". One study(19) reports important meanings to be considered in the nursing care provided to individuals who underwent myocardial revascularization. The meanings of such care are related to the maintenance of friendly, trustful relationships that provide emotional support to overcome family absences and changes in lifestyle.

\section{Conclusion}

This study enabled a better understanding of the aspects related to the intensity and sites of pain in the postoperative period of cardiac surgery during rest and while performing certain activities. Therefore, it supports other studies and new approaches to managing pain. The identification of specific aspects of this type of pain enables health professionals to plan and develop appropriate, individualized and humanized care. The appropriate control of pain after cardiac surgery is necessary in order to avoid delayed recovery from surgery.

The experience of pain is subjective, complex, and multidimensional. Hence, to effectively manage this phenomenon, a multidisciplinary approach is needed to include alternative treatments in addition to the traditional ones and continually investigate how appropriate methods to alleviate pain are, considering both positive and negative aspects.

\section{References}

1. Chung JWY, Lui JCZ. Postoperative pain management: study of patients level of pain and satisfaction with health are providers responsiveness to their reports of pain. Nurs Health Sci. 2003 Mar;5(1):13-21.

2. Milgrom LB, Brooks JA, Qi R, Brunnell K, Wuestfeld

$S$, Beckman D. Pain Levels Experienced With Activities After Cardiac Surgery. Am J Crit Care. 2004; 13(2):116-25.

3. Santos EMM, Pimenta CAM. Contradições entre o relato de dor no pós-operatório e a satisfação do doente com a analgesia. Rev Bras Cancerol. 2000; 46(1): 93-104.

4. Couceiro TCM, Valença MM, Lima LC, Menezes TC, Raposo MCF. Prevalência e influência do sexo, idade e tipo de operação na dor pós-operatória. Rev Bras Anestesiol. mai-jun 2009;59(3):314-20.

5. Bruce J, Drury N, Poobalan AS, Jeffrey RR, Smith WC, Chambers WA. The prevalence of chronic chest and leg pain following cardiac surgery: a historical cohort study. Pain. 2003;104(1-2):265-73.
6. Taillefer MC, Carrier M, Bélisle S, Levesque S, Lanctôt $\mathrm{H}$, Boisvert AM, et al. Prevalence, characteristics, and predictors of chronic nonanginal postoperative pain after cardiac operation: a cross-sectional study. J Thorac Cardiovasc Surg. 2006;131(6):1274-80.

7. Lahtinen P, Kokki H, Hynynen M. Pain after Cardiac Surgery. A Prospective Cohort Study of 1-Year Incidence and Intensity. Anesthesiology. 2006;105(4):794-800.

8. Younger J, Mccue R, Mackey S. Pain Outcomes: A Brief Review of Instruments and Techniques. Curr Pain Headache Rep. 2009 Feb;13(1):39-43.

9. Sousa FF, Pereira LV, Cardoso R, Hortense P. Multidimensional pain evaluation scale. Rev. Latino-Am. Enfermagem. 2010;18(1):3-10.

10. World Health Organization. Global Database on Body Mass Index. BMI Classification [Internet]. Geneva; 2008. [acesso $10 \mathrm{dez}$ 2012]. Disponível em: http:// www.who.int/bmi/index.jsp?introPage=intro_3.html

11. Rocha LA, Maia TF, Silva LF. Diagnósticos de enfermagem em pacientes submetidos à cirurgia cardíaca. Rev Bras Enferm. mai-jun 2006; 59(3):321-6.

12. Yorke J, Wallis M, Mclean B. Patients' perceptions of pain management after cardiac surgery in an Australian critical care unit. Heart Lung. 2004;33(1):33-41.

13. Baumgarten MCS, Garcia GK, Frantzeski MH, Giacomazzi CM, Lagni VB, Dias AS, et al. Comportamento da dor e da função pulmonar em pacientes submetidos à cirurgia cardíaca via esternotomia. Rev Bras Cir Cardiovasc. dez 2009;24(4):497-505.

14. Andrade EV, Barbosa M, Barichello E. Pain assessment in postoperative cardiac surgery. Acta Paul Enferm. 2010;23(2):224-9.

15. Morais DB, Lopes ACR, Sá VM, Silva WM Junior, Manoel CN, et al. Avaliação do Desempenho Funcional em Pacientes Submetidos à Cirurgia Cardíaca. Rev Bras Cardiol. 2010;23(5):263-9.

16. Sasseron AN, Figueiredo LC, Trova K, Cardoso AL, Lima NMFV, Olmos SC, et al. A dor interfere na função respiratória após cirurgias cardíacas? Rev Bras Cir Cardiovasc. 2009;24(4):490-6.

17. Mueller XM, Tinguely F, Tevaearai HT, Revelly JP, Chioléro R, Von Segesser LK. Pain location, distribution, and intensity after cardiac surgery. Chest. 2000;118(2):391-6.

18. Mota FA, Marcolan JF, Pereira MH, Milanez AM, Dallan LA, Diccini S. et al. Comparison study of two different patient-controlled anesthesia regiments after cardiac surgery. Rev Bras Cir Cardiovasc. 2010; 25(1):38-44. 
19. Erdmann AL, Lanzoni GMM, Callegaro GD, Baggio MA, Koerich $\mathrm{C}$. Understanding the process of living as signified by myocardial revascularization surgery patients. Rev. Latino-Am. Enfermagem. [Internet]. 2013 Fev [acesso 20 jul 2013] ; 21(1): 332-9. Disponível em: http:// www.scielo.br/scielo.php?script=sci_arttext\&pid=S0104$11692013000100007 \&$ lng =pt. http://dx.doi.org/10.1590 /S0104-11692013000100007 